\title{
Comparison Study of Analysis of Water Tower Structure Using Finite Element Method and Engineering Equation Solver
}

\author{
Nanang Qosim*), Putra Mulya Pamungkas, Barkah Fitriyana, Wanda Pratomo, Marthan Lassandy \\ Departemen Teknik Mesin, Fakultas Teknik, Universitas Indonesia \\ Kampus Baru UI Depok, 16424 Depok, Jawa Barat \\ *E-mail: nanang.qosim@ui.ac.id
}

\begin{abstract}
Abstrak
Studi ini bertujuan untuk membandingkan hasil analisis nilai deformasi dan tegangan maksimum pada struktur tower penyangga tendon air dengan penerapan metode elemen hingga dan engineering equation solver (EES). Hasil simulasi menunjukkan bahwa verifikasi berhasil dilakukan ditandai dengan nilai deformasi yang didapatkan konvergen menuju nilai tertentu dengan maksimal persentase 0,40\%. Selanjutnya, nilai tegangan maksimum yang terjadi masih berada di bawah allowable stress material $160 \mathrm{MPa}$, sehingga struktur tower penyangga toren dengan kapasitas 500 liter aman untuk digunakan. Hasil perhitungan dengan mengunakan EES menunjukkan bahwa nilai deformasi yang terjadi adalah sebesar 1,70 mm. Nilai ini berbeda 0,31 atau 18,24\% jika dibandingkan dengan nilai deformasi sebesar 2,01 mm dengan menggunakan fine meshing pada ANSYS.
\end{abstract}

Kata kunci: tower penyangga toren; metode elemen hingga; EES; deformasi; tegangan

\begin{abstract}
This study aims to compare the analysis results of the maximum deformation and maximum stress on water structure using finite element method and engineering equation solver (EES). Simulation results show that verification successfully performed, with deformation value obtained is convergent to certain value with maximum percentage of 0,40\%. Further, the maksimum stress value is still under the allowable stress of material $160 \mathrm{MPa}$. Hence, the structure of water tower with a capacity of 500 liters is safe to use. The result of calculation using EES shows that the deformation value is $1.70 \mathrm{~mm}$. This value is different about 0.31 or $18.24 \%$ compared to the deformation value of $2.01 \mathrm{~mm}$ using fine meshing on ANSYS.
\end{abstract}

Keywords: water tower; finite element method; EES; deformation; stress

\section{PENDAhULUAN}

Di zaman yang serba instan seperti sekarang tentu masyarakat ingin sesuatu yang lebih mudah dan cepat, termasuk dalam penyimpanan air. Jika dulu orang banyak yang memakai bak terbuka dengan cor untuk tempat mengisi air atau bahkan menggunakan air dari mesin pompa langsung, namun kini sudah banyak yang memilih untuk menggunakan tandon atau tangki air. Dengan memakai tandon air tersebut kita bisa menyimpan air lebih mudah dan dapat digunakan kapanpun. Namun untuk bisa mengalir ke kran dengan baik, kita harus menaruh tandon air di tempat yang lebih tinggi. Ada dua cara yang bisa dilakukan, yang pertama yaitu dengan menaruh di lantai atas jika rumah bertingkat, sedangkan cara yang kedua yaitu membangun sebuah menara khusus tandon air.

Ketika dalam suatu keadaan ingin digunakan tandon air ini, maka harus dipersiapkan tempat tandon tersebut. Tandon ini harus diletakkan di ketinggian, agar air dapat dengan mudah mengalir ke bawah. Salah satu cara untuk menaruh tandon air tersebut adalah dengan membuat tempat khusus yang sering disebut dengan menara tandon air. Dalam pembuatan konstruksi menara tandon air menggunakan besi sebagai bahan utamanya, besi ini dipilih karena selain mempunyai sifat yang kuat, besi juga mudah dijumpai serta mudah untuk dibentuk. Hal pertama yang harus dilakukan untuk merencanakan menara penyangga tendon air adalah dengan membuat konsep desain menara tandon air tersebut, dalam pembuatan konsep ini sebaiknya dibuat berdasarkan lokasi penempatannya agar ketika nanti sudah jadi akan mudah dilakukan pemasangan. Dengan membuat konstruksi menara tandon, diharapkan dapat memperlancar aliran air tersebut serta tidak perlu lagi bingung tempat untuk menaruh tandon air tersebut.

Selanjutnya, penggunaan FEM dalam pemodelan desain dan analisis struktur menjadi semakin penting seiring dengan penggunaan standar atau kode tertentu dari perancangan suatu struktur. Dalam pengkonsepan ini, dilakukan beberapa hal meliputi desain awal, simulasi, dan analisis hasil data. Hasil data dibatasi pada tegangan dan lendutan yang dibandingkan antara hasil menggunakan EES dengan ANSYS.

Dalam melakukan perancangan struktur tower penyanngga tendon air perlu dilakukan perhitungan dari beban-beban yang mungkin terjadi terhadap struktur 
tersebut untuk selanjutnya dapat dilakukan efisiensi baik terhadap struktur maupun material tower tersebut. Oleh karena itu, perlu dilakukan fokus riset lebih lanjut untuk mengembangkan desain tower penyangga tandon air, salah satunya dengan melakukan pemodelan FEM pada desain strukturnya.

\section{TINJAUAN PUSTAKA}

\section{Metode Elemen Hingga}

Metode elemen hingga (finite element) merupakan salah satu metode numerik yang dapat digunakan untuk menyelesaikan masalah struktural, termal dan elektromagnetik. Dalam metode ini seluruh masalah yang kompleks seperti variasi bentuk, kondisi batas dan beban diselesaikan dengan metode pendekatan [1]. Karena keanekaragaman dan fleksibilitas sebagai perangkat analisis, metode ini mendapat perhatian dalam dunia teknik. Konsep dasar finite element adalah mendiskretisasi atau membagi suatu struktur menjadi bagian-bagian yang lebih kecil atau yang disebut elemen yang jumlahnya berhingga, kemudian melakukan analisis gabungan terhadap elemen-elemen kecil tersebut.

Tujuan dari FEM adalah untuk memperoleh nilai pendekatan numerik sehingga dapat diselesaikan dengan bantuan komputer, maka FEM dikatakan bersifat komputer oriented [2]. Saat ini pengunaan FEM untuk menghitung dan mensimulasikan model dengan bantuan komputer mengalami perkembangan yang sangat pesat. Hal ini dikarenakan perkembangan hardware komputer yang sangat pesat pula, sehingga mendukung proses perhitungan dengan metode numerik. Keuntungan menggunakan FEM adalah efisiensi dalam persamaan numerik dan dapat diterapkan dalam banyak tipe analisis.

Perkembangan pesat dari teknologi komputer mendorong terus mendorong meotde ini, karena komputer dibutuhkan sebagai perangkat aplikasi dari metode numerik. Diantara software paket yang populer untuk analisis metode numerik adalah STAAD-PRO, GT-STRUDEL, NASTRAN, NISA and ANSYS. Dengan menggunakan software ini dapat menganalisis struktur yang kompleks. Variabel dasar atau variabel medan yang tidak diketahui yang ditentukan dalam masalah teknik adalah pergeseran dalam mekanik solid, kecepatan dalam mekanika fluida, potensial listrik dan magnet dalam teknik listrik dan suhu dalam aliran panas. Secara kontinu variabel yang tidak diketahui ini tidak terbatas.

Prosedur elemen hingga mengurangi variabel yang tidak diketahui menjadi sejumlah berhingga dengan membagi daerah penyelesaian menjadi bagian kecil yang disebut elemen dan dinyatakan sebagai variabel medan yang tidak diketahui dalam istilah dianggap sebagai fungsi pendekatan (approximation functions/interpolation functions/shape functions) dalam setiap elemen. Fungsi pendekatan didefinisikan sebagai medan variabel dari titik-titik tertentu yang disebut node atau titik node [3]. Variabel medan dapat ditentukan pada beberapa titik menggunakan fungsi interpolasi. Setelah memilih elemen dan variabel titik yang tidak diketahui selanjutnya menyusun sifat bahan (properties) elemen untuk setiap elemen. Contohnya dalam mekanika solid pada pergeseran gaya kita menemukan adanya karakteristik kekakuan (stifness characteristics) masing-masing elemen. Secara matematika hubungan ini dapat dibentuk sebagai berikut [4]:

$[\mathrm{k}] \mathrm{e}\{\tilde{\mathrm{o}}\} \mathrm{e}=\{\mathrm{F}\} \mathrm{e}$

Dimana [k]e adalah matriks kekakuan, $\{\delta\}$ e vektor pergeseran node dari elemen dan $\{\delta\}$ e adalah vektor gaya node.

\section{Engineering Equation Solver (EES)}

EES merupakan suatu software computer yang dapat membantu untuk melakukan kalkulasi dari sekumpulan persamaan aljabar. EES juga mampu untuk menyelesaikan persamaan diferensial, persamaan dengan variable kompleks, melakukan optimasi, memberikan regresi linier dan non-linier.

Cara kerja dari EES adalah menyelesaikan persamaan secara simultan. Hal ini untuk menyederhanakan proses dan memastikan EES bekerja secara optimal. EES juga menyediakan banyak buit-in fungsi property matematis dan termophysical yang berguna untuk perhitungan teknik.

Dalam penggunaan EES dapat dimasukkan hubungan fungsionalnya sendiri dalam tiga cara, yaitu: (1) Fasilitas untuk memasukkan dan menginterpolasi data tabular disediakan, sehingga data table dapat langsung digunakan dalam solusi dari rangkaian persamaan; (2) Bahasa EES mendukung fungsi dan prosedur penulisan pengguna yang serupa dengan yang ada pada software PASCAL dan FORTRAN. EES juga menyediakan dukungan modul yang ditulis pengguna, yang merupakan program EES yang dapat diakses oleh program EES lainnya. Fungsi, prosedur dan modul dapat disimpan sebagai file perpustakaan atau template yang dapat dibaca secara otomatis saat EES dimulai; (3) Fungsi dan prosedur eksternal yang ditulis dalam Bahasa tingkat tinggi seperti PASCAL, C atau FORTRAN dapat dihubungkan secara dinamis ke EES dengan menggunakan kemampuan perpustakaan link dinamis (dynamic link library) yang tergabung delam system operasi Windows.

\section{METODE}

\section{Bahan dan Alat}

Di dalam studi ini bahan/material yang dipakai dalam struktur tower penyangga tendon air kapasitas 500 liter, yang akan di uji menggunakan software EES dan ANSYS adalah structural steel dengan properties seperti yang dijelaskan pada pembahasan selanjutnya.

Sedangkan alat yang digunakan adalah seperangkat komputer dengan spesifikasi Operating System: Windows 7 Ultimate, Processor intel i7, 3,2 Ghz, Memory (RAM): 8 GB, System Type: 64-bit Operating System, Monitor 15 Inch. Software solver yang dipakai 
adalah EES, dan software analysis yang dipakai adalah ANSYS Student version.

\section{Identifikasi Struktur}

Dari hasil observasi, diperoleh bahwa material yang digunakan adalah structural steel sehingga dapat diketahui propertiesnya untuk digunakan sebagai inputan data material pada software ANSYS dalam melakukan analisis beban statis maupun dinamis. Kondisi penyambungan material sebagian besar menggunakan las, sehingga bisa dianggap struktur tersebut homogen dalam proses analisis.

\section{Perhitungan dengan EES}

Terdapat beberapa windows yang akan digunakan dalam perhitungan menggunakan EES ini, yaitu [5]:

a. Equation window, pada window ini, persamaan yang akan diselesaikan ditulis seperti biasa, tanpa adanya Bahasa tingkat tinggi.

b. Diagram window, untuk menampilkan grafik dan teks yang berkaitan dengan masalah yang sedang dipecahkan, sehingga mempermudah pemahaman dalam menyelesaikan permasalahan. Diagram window juga dapat memberikan informasi input dan output yang mudah digunakan.

c. Solution window, akan secara otomatis muncul didepan semua window lain setelah melakukan perhitungan. Nilai dan satuan semua variable yang muncul di equation window akan ditampilkan secara alfabetis dengan menggunakan sebanyak mungkin kolom yang sesuai di seluruh window.

d. Array Window, variabel array ini lebih banyak penggunaannya sebagai input matriks, yang diketik dengan indeks dalam tanda kurung siku, misalnya $\mathrm{X}[1]$ dan $\mathrm{Y}[2 ; 3]$. Hasil perhitungan dalam bentuk matriks tidak akan keluar pada Solution window, melainkan akan tampil pada Array window.

\section{Analisis dengan FEM}

Analisis dengan FEM dilakukan dengan mengikuti tahapan berikut, yaitu:

a. Pemodelan geometri, dalam hal ini model awal dibuat menggunakan Solidworks kemudian dilakukan remodeling untuk dapat diinputkan kedalam software ANSYS. Dalam pembuatan geometri model juga diinputkan data material yang digunakan.

b. Meshing control. Sebelum dilakukan proses meshing maka dilakukan pengaturan terlebih dahulu seperti menentukan size elemen, tingkat kehalusan elemen, dan lain sebagainya.

c. Menentukan kondisi pembebanan yang akan diberikan berdasarkan kondisi real yang saat pengoperasian.

d. Memberikan inputan solusi pada analisis statik seperti deformasi yang dihasilkan, serta force.

e. Langkah terakhir adalah didapatkan hasil dari simulasi pembebanan.

\section{PEMODELAN}

\section{Properti Material}

Material yang digunakan untuk struktur tower penyangga tendon air kapasitas 500 liter adalah structural steel dengan properti seperti pada Gambar 1 .

\begin{tabular}{|c|c|c|}
\hline Property & Value & Unit \\
\hline Density & 7850 & $\mathrm{~kg} \mathrm{~m}^{\wedge}-3$ \\
\hline \multicolumn{3}{|l|}{ 日诸 Isotropic Secant Coefficient of Thermal Expansion } \\
\hline 7 Coefficient of Thermal Expansion & $1,2 \mathrm{E}-05$ & $\mathrm{C}^{\wedge}-1$ \\
\hline 7 Reference Temperature & 22 & c \\
\hline \multicolumn{3}{|l|}{$\square$ Isotropic Elasticity } \\
\hline Derive from & Young's Modulus and... $\quad \pm$ & \\
\hline Young's Modulus & $2 \mathrm{E}+11$ & $\mathrm{~Pa}$ \\
\hline Poisson's Ratio & 0,3 & \\
\hline Bulk Modulus & $1,666 \pi+11$ & $\mathrm{~Pa}$ \\
\hline Shear Modulus & $7,6923 E+10$ & $\mathrm{~Pa}$ \\
\hline I 7 Field Variables & & \\
\hline I Alternating Stress Mean Stress & Tabular & \\
\hline \pm Strain-Life Parameters & & \\
\hline 7 Tensile Yield Strength & $2,5 E+08$ & $\mathrm{~Pa}$ \\
\hline 7 Compressive Yield Strength & $2,5 E+08$ & $\mathrm{~Pa}$ \\
\hline 7 Tensile Ultimate Strength & $4,6 E+08$ & $\mathrm{~Pa}$ \\
\hline 7 Compressive Ultimate Strength & 0 & $\mathrm{~Pa}$ \\
\hline
\end{tabular}

Gambar 1. Properties material structural steel

\section{Pembebanan}

Pembebanan yang diberikan pada struktur tower penyangga tendon air adalah berdasarkan kapasitasnya yaitu 500 liter. Sehingga pembebanan yang terjadi adalah $5000 \mathrm{~N}$.

\section{Pemodelan}

Dalam studi ini, dilakukan dua jenis pemodelan mengunakan software EES dan ANSYS. Masingmasing pemodelan tersebut adalah sebagai berikut:

1) Pemodelan pada EES

Free body diagram untuk perhitungan pada software EES adalah seperti ilustrasi pada Gambar 2. Beam dibagi menjadi 2 elemen dengan 3 nodes. Adapun gaya yang diasumsikan adalah gaya dengan distribusi merata sepanjang batang beam.

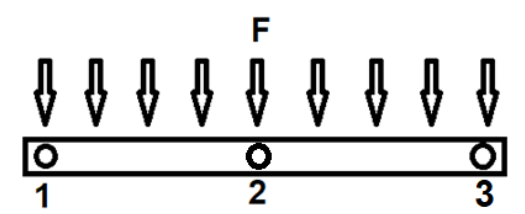

Gambar 2. Free body diagram struktur

Pemodelan pada EES yakni dengan menggunakan elemen beam 1D yang bekerja pada bidang 2D. Gambar 3 merupakan persamaan-persamaan nilai yang diketahui dan diinput ke dalam equation windows pada EES. Nilai yang diketahui meliputi modulus young, inersia, luasan, panjang, serta beban yang terjadi pada struktur. 


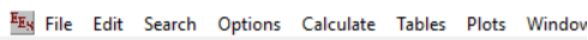

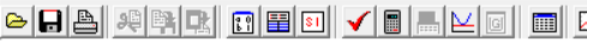

$$
\begin{aligned}
& \{\text { Nilai yang diketahui }\} \\
& F 1 x=0 \\
& F 1 y=\left(\left(q^{*} L 1\right) / 2\right) \\
& F 2 x=0 \\
& F 2 y=\left(q^{*}(L 1+L 2)\right) \\
& F 3 x=0 \\
& F 3 y=\left(\left(q^{*} L 2\right) / 2\right) \\
& M 2=0 \\
& M 1=-\left(q^{*}\left(L 1^{\wedge} 2\right)\right) / 12 \\
& M 3=\left(q^{*}\left(L 2^{\wedge} 2\right)\right) / 12
\end{aligned}
$$

Gambar 3. Persamaan-persamaan dan variabel input

\section{2) Pemodelan pada ANSYS}

Pemodelan pada software ANSYS menggunakan elemen beam 2D. Sebelum pemodelan dilakukan pada daerah yang memiliki deformasi maksimal, maka akan dilakukan dulu simulasi keseluruhan pada struktur seperti pada Gambar 4.

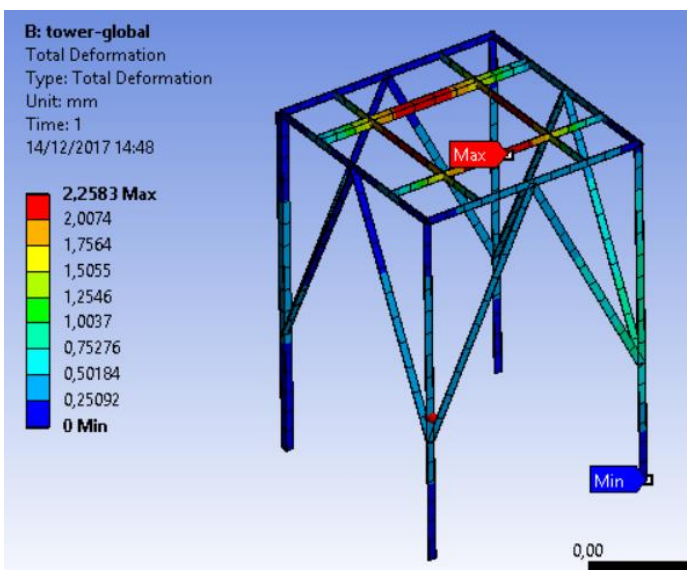

Gambar 4. Deformasi yang terjadi pada struktur tower

Simualasi keseluruhan dilakukan dengan menggunakan elemen 1D dan dengan coarse meshing hanya untuk mengetahui lokasi maksimum deformasi. Dari Gambar 4, dapat dilihat bahwa deformasi maksimum sebesar 2,2583 $\mathrm{mm}$ terletak pada bagian tengah beam (ditandai dengan spectrum warna merah).

Dengan demikian, fokus pada studi ini adalah akan dibuat pemodelan elemen 2D beam dengan bantuan software ANSYS untuk beam horizontal seperti yang ditunjukkan oleh simbol Max (warna merah) pada Gambar 5. Pemodelan akan dilakukan memberikan initial condition pada node 1 dan 3 .

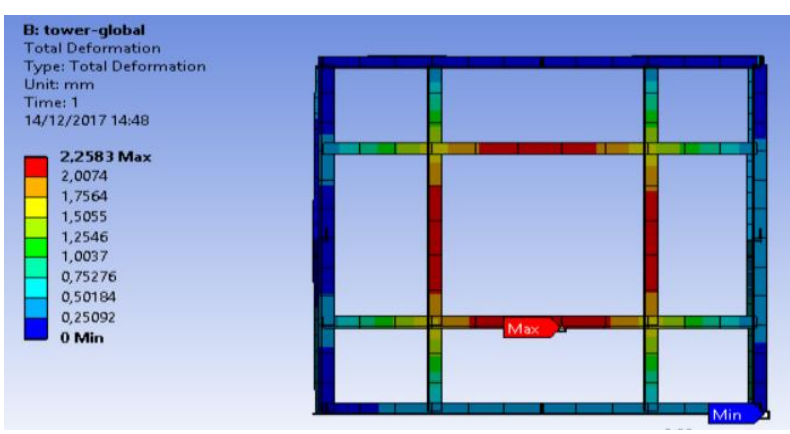

Gambar 5. Bagian yang akan dilakukan pemodelan 2D (ditandai simbol Max.)
Detail dimensi elemen beam untuk pemodelan 2D adalah seperti pada Gambar 6.

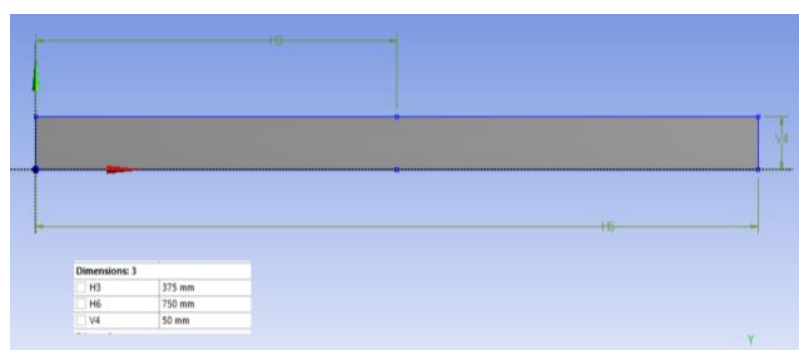

Gambar 6. Dimensi elemen beam 2D

Pada pemodelan struktur tower penyangga toren, seperti yang telah dibahas sebelumnya, beban yang terjadi adalah sebesar $5000 \mathrm{~N}$ yang terbagi secara merata pada 4 penyangga. Sehingga beban yang dimasukkan pada elemen ini adalah sebesar $1250 \mathrm{~N}$ (Gambar 7).

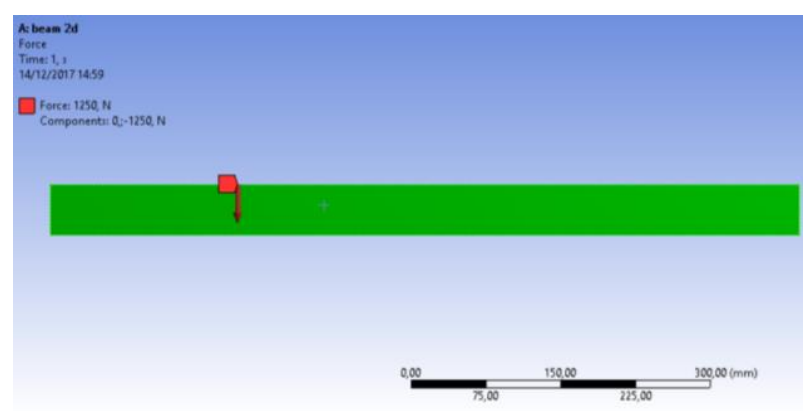

Gambar 7. Lokasi dan besarnya pembebanan yang diberikan

Pemberian initial condition mengacu pada pemodelan global beam sebelumnya. Data initial condition diambil dari data deformasi pada probe 3 dan probe 4 (Gambar 8) dengan data sebagai berikut:

Tabel 1. Nilai probe 1 dan 2 pada sumbu x dan y

\begin{tabular}{|c|c|c|}
\hline & Sumbu x $(\mathbf{m m})$ & Sumbu y (mm) \\
\hline Probe 1 & $-5,0819 \mathrm{e}-002$ & $-1,6694$ \\
\hline Probe 2 & $-5,0819 \mathrm{e}-002$ & $-1,6694$ \\
\hline
\end{tabular}

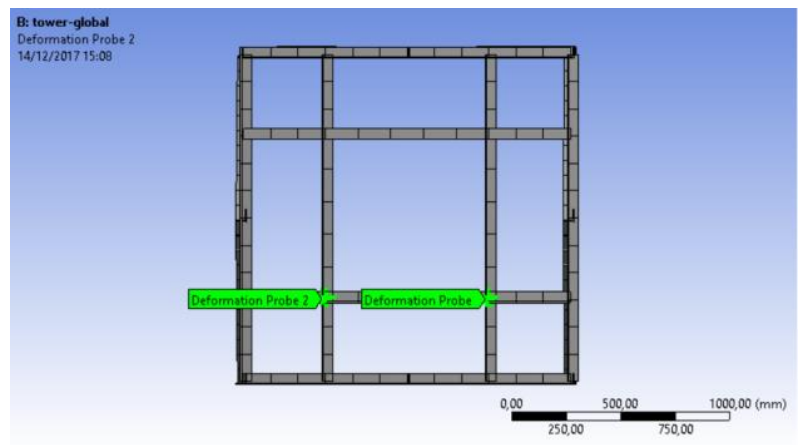

Gambar 8. Lokasi probe 1 dan 2 


\section{VERIFIKASI}

\section{Meshing Coarse}

Pengaturan meshing coarse yang digunakan baik untuk kasus fixture maupun kasus initial condition adalah sebagaimana ditampilkan pada Gambar 9 dan 10. Pada meshing coarse jumlah node sebanyak 99, dan jumlah elemen 64 buah dengan jenis elemen berupa elemen segi empat.

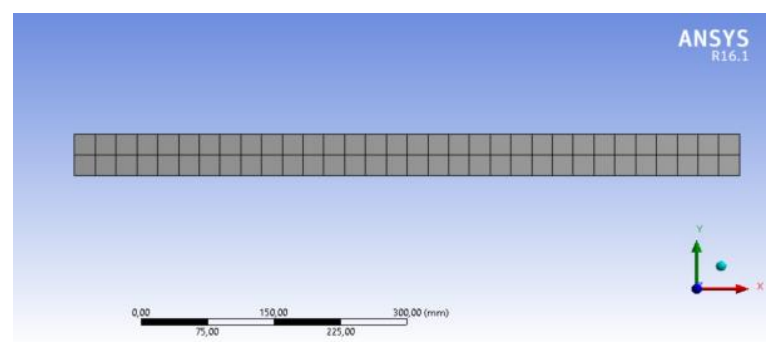

Gambar 9. Meshing coarse

\begin{tabular}{|c|c|c|}
\hline \multicolumn{3}{|c|}{ Details of "Mesh" } \\
\hline \multicolumn{3}{|c|}{ Display } \\
\hline & Display Style & Body Color \\
\hline \multicolumn{3}{|c|}{ Defaults } \\
\hline & Physics Preference & Mechanical \\
\hline & $\square$ Relevance & 0 \\
\hline \multicolumn{3}{|c|}{ Sizing } \\
\hline & Use Advanced Size Function & On: Curvature \\
\hline & \begin{tabular}{|l|} 
Relevance Center \\
\end{tabular} & Coarse \\
\hline & Initial Size Seed & Active Assembly \\
\hline & Smoothing & Low \\
\hline & Span Angle Center & Coarse \\
\hline & Curvature Normal Angle & Default $\left(30,0^{\circ}\right)$ \\
\hline & Min Size & Default $(4,84120 \mathrm{~mm})$ \\
\hline & Max Face Size & Default $(24,2060 \mathrm{~mm})$ \\
\hline & Growth Rate & Default \\
\hline & Number of Retries & Default (4) \\
\hline & Extra Retries For Assembly & Yes \\
\hline & Rigid Body Behavior & Dimensionally Reduced \\
\hline & Mesh Morphing & Disabled \\
\hline \multicolumn{3}{|c|}{ Defeaturing } \\
\hline & Use Sheet Thickness for Pi... & No \\
\hline & Pinch Tolerance & Default $(4,35710 \mathrm{~mm})$ \\
\hline & Generate Pinch on Refresh & No \\
\hline & Sheet Loop Removal & No \\
\hline & Automatic Mesh Based Def... & On \\
\hline & $\square$ Defeaturing Tolerance & Default $(3,63090 \mathrm{~mm})$ \\
\hline \multicolumn{3}{|c|}{ Statistics } \\
\hline & $\square$ Nodes & 99 \\
\hline & Elements & 64 \\
\hline & Mesh Metric & None \\
\hline
\end{tabular}

Gambar 10. Detail meshing coarse

\section{Meshing Medium}

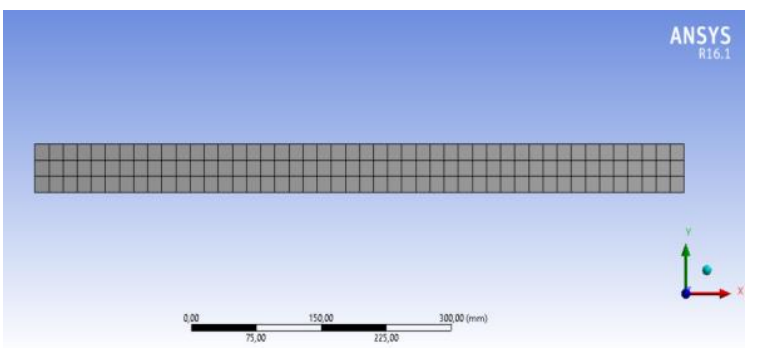

Gambar 11. Meshing medium

\begin{tabular}{|c|c|c|}
\hline \multicolumn{3}{|c|}{ Details of "Mesh" } \\
\hline \multicolumn{3}{|c|}{ Display } \\
\hline & Display Style & Body Color \\
\hline \multicolumn{3}{|c|}{ Defaults } \\
\hline & Physics Preference & Mechanical \\
\hline & $\square$ Relevance & 50 \\
\hline \multicolumn{3}{|c|}{ Sizing } \\
\hline & Use Advanced Size Function & On: Curvature \\
\hline & \begin{tabular}{|l} 
Relevance Center \\
\end{tabular} & Medium \\
\hline & Initial Size Seed & Active Assembly \\
\hline & Smoothing & Medium \\
\hline & Span Angle Center & Coarse \\
\hline & $\square$ Curvature Normal Angle & Default $\left(30,0^{\circ}\right)$ \\
\hline & Min Size & Default $(3,32830 \mathrm{~m} .$. \\
\hline & Max Face Size & Default $(16,6420 \mathrm{~m} .$. \\
\hline & Growth Rate & Default \\
\hline & Number of Retries & Default (4) \\
\hline & Extra Retries For Assembly & Yes \\
\hline & Rigid Body Behavior & Dimensionally Red... \\
\hline & Mesh Morphing & Disabled \\
\hline \multicolumn{3}{|c|}{ - Defeaturing } \\
\hline & Use Sheet Thickness for Pinch & No \\
\hline & Pinch Tolerance & Default $(2,99550 \mathrm{~m} .$. \\
\hline & Generate Pinch on Refresh & No \\
\hline & Sheet Loop Removal & No \\
\hline & Automatic Mesh Based Defeaturing & On \\
\hline & $\square$ Defeaturing Tolerance & Default $(2,49630 \mathrm{~m} .$. \\
\hline \multicolumn{3}{|c|}{ Statistics } \\
\hline & $\square$ Nodes & 188 \\
\hline & Elements & 138 \\
\hline & Mesh Metric & None \\
\hline
\end{tabular}

Gambar 12. Detail meshing medium

Pengaturan meshing medium yang digunakan baik untuk kasus fixture maupun kasus initial condition adalah sebagaimana ditampilkan pada Gambar 11 dan 12. Pada meshing medium jumlah node sebanyak 188 , dan jumlah elemen 138 buah dengan jenis elemen berupa elemen segi empat.

\section{Meshing Fine}

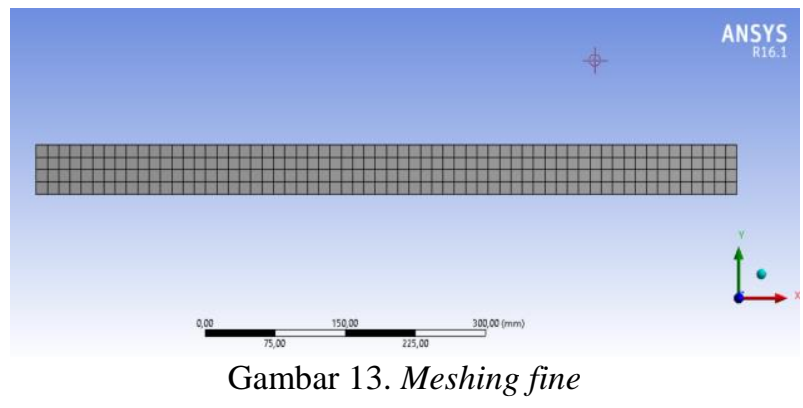

Pengaturan meshing fine yang digunakan baik untuk kasus fixture maupun kasus initial condition yakni sebagai berikut pada Gambar 13 dan 14. Pada meshing fine jumlah node sebanyak 315, dan jumlah elemen 248 buah dengan jenis elemen berupa elemen segi empat. 


\begin{tabular}{|c|c|c|}
\hline \multicolumn{3}{|c|}{ Details of "Mesh" } \\
\hline \multicolumn{3}{|c|}{$\square$ Display } \\
\hline & Display Style & Body Color \\
\hline \multicolumn{3}{|c|}{ Defaults } \\
\hline & Physics Preference & Mechanical \\
\hline & $\square$ Relevance & 100 \\
\hline \multicolumn{3}{|c|}{ Sizing } \\
\hline & Use Advanced Size Function & On: Curvature \\
\hline & \begin{tabular}{|l|} 
Relevance Center \\
\end{tabular} & Fine \\
\hline & Initial Size Seed & Active Assembly \\
\hline & Smoothing & High \\
\hline & Span Angle Center & Coarse \\
\hline & $\square$ Curvature Normal Angle & Default $\left(30,0^{\circ}\right)$ \\
\hline & $\square$ Min Size & Default $(2,42060 \mathrm{~m} \ldots$ \\
\hline & $\square$ Max Face Size & Default $(12,1030 \mathrm{~m} \ldots$ \\
\hline & $\square$ Growth Rate & Default \\
\hline & Number of Retries & Default (4) \\
\hline & Extra Retries For Assembly & Yes \\
\hline & Rigid Body Behavior & Dimensionally Red... \\
\hline & Mesh Morphing & Disabled \\
\hline \multicolumn{3}{|c|}{ Defeaturing } \\
\hline & Use Sheet Thickness for Pinch & No \\
\hline & Pinch Tolerance & Default $(2,17860 \mathrm{~m} \ldots$ \\
\hline & Generate Pinch on Refresh & No \\
\hline & Sheet Loop Removal & No \\
\hline & Automatic Mesh Based Defeaturing & On \\
\hline & $\square$ Defeaturing Tolerance & Default $(1,81550 \mathrm{~m} \ldots$ \\
\hline \multicolumn{3}{|c|}{ Statistics } \\
\hline & $\square$ Nodes & 315 \\
\hline & $\square$ Elements & 248 \\
\hline & Mesh Metric & None \\
\hline
\end{tabular}

Gambar 14. Detail meshing fine

\section{HASIL DAN PEMBAHASAN}

\section{Hasil Perhitungan dengan EES}

Gambar 15 merupakan persamaan-persamaan dan nilai yang diketahui dan diinput ke dalam equation windows pada EES. Nilai yang diketahui meliputi modulus young, inersia, luasan, panjang, serta beban yang terjadi pada struktur. Pada Gambar 15 juga ditampilkan matriks kekakuan local untuk tiap-tiap elemen. Matriks kekakuan lokal k1 merupakan matriks yang terbentuk dari node 1 dan 2 pada elemen 1 . Sementara matriks kekakuan lokal k2 merupakan persamaan matriks yang terbentuk dari node 2 dan node 3 elemen 2 dari pemodelan di software EES.

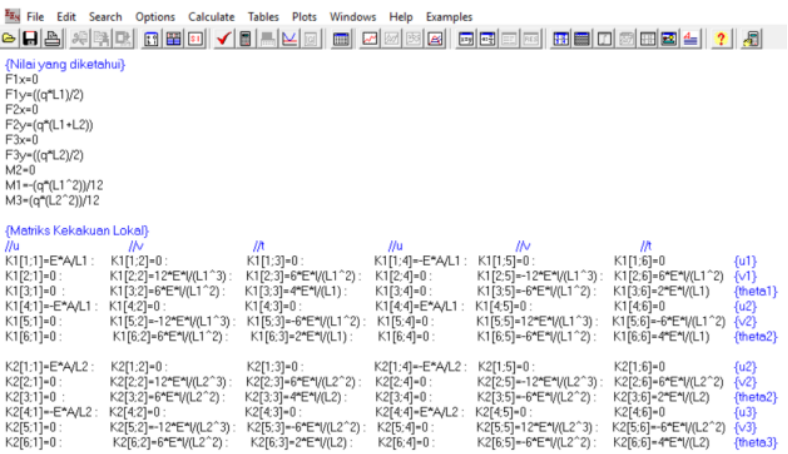

Gambar 15. Variabel input dan matriks kekakuan lokal tiap elemen

Dari matriks kekakuan lokal tiap elemen tersebut, selanjutnya disusun matrik kekakuan global, Gambar 16, dan dieliminasi sesuai boundary conditions yang diberikan. Nilai u1, v1, dan u3, v3 didapatkan dari hasil probe ANSYS global sebagai initial condition pada pemodelan.

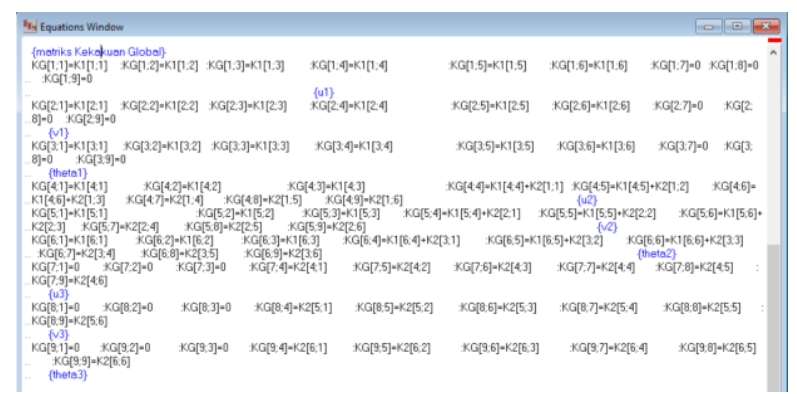

Gambar 16. Susunan matriks kekakuan global

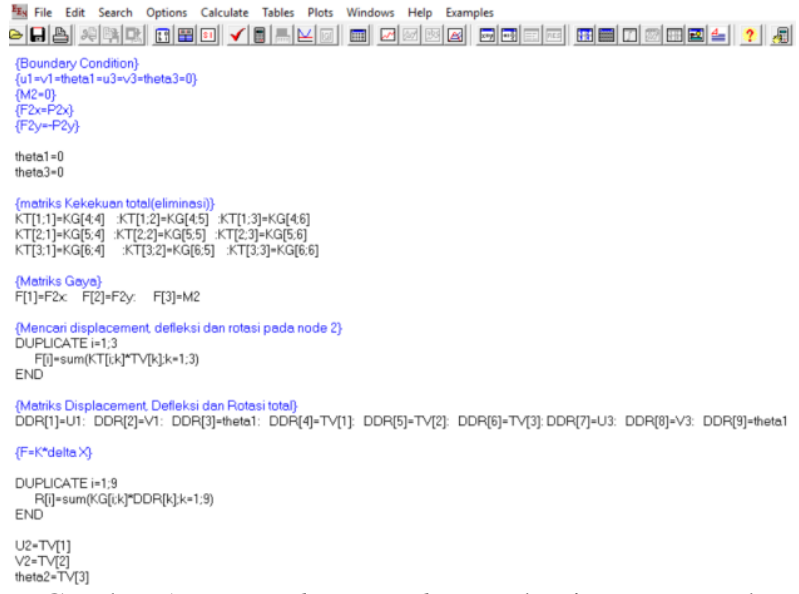

Gambar 17. Boundary conditions dan inputan untuk mencari variabel output

Selanjutnya pada Gambar 17 merupakan matriks kekakuan total yang didapat setelah mengeliminasi persamaan matriks kekakuan global setelah boundary condition dimasukkan, sehingga yang tersisa hanya matriks kekakuan total $3 \times 3$. Langkah selanjutnya adalah membuat persamaan untuk mencari defleksi dan gaya reaksi yang terjadi (Gambar 17).

Gambar 18, 19, dan 20 merupakan hasil solving kasus yang disajikan masing-masing sebagai main solution, array windows, dan diagram windows. Pada Gambar 8 dapat dilihat bahwa pada kolom DRi yang berarti displacement rotation pada node 1 dan 3 merupakan nilai initial condition yang dimasukkan. Sedangkan kolom Ri merupakan kumpulan gaya reaksi yang terjadi pada node 1 sampai node 3 . Pada diagram windows (Gambar 9) node 2 memiliki nilai displacement terbesar yaitu $-0,001648 \mathrm{~m}$ atau $1,648 \mathrm{~mm}$ pada arah sumbu Y negatif (ke bawah). 


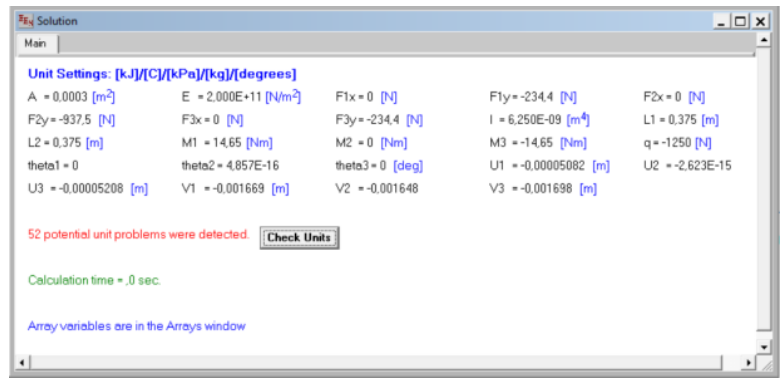

Gambar 18. Hasil solving utama pada jendela solution

\begin{tabular}{|c|c|c|c|c|c|c|c|}
\hline \multicolumn{7}{|c|}{ Eyy Arrays Table } & $-x$ \\
\hline Sort & $\mathrm{KG}_{\mathrm{q}}$ & $\mathrm{DDR}_{\mathrm{i}}$ & $\mathrm{TV}_{\mathrm{i}}$ & $R_{i}$ & $\mathrm{KT}_{\mathrm{i} 1}$ & $\mathrm{KT}_{\mathrm{i}_{2}}$ & $\kappa T_{L_{13}}$ \\
\hline [1] & 0 & $-0,00005082$ & $-2,623 \mathrm{E}-15$ & -8131 & $3.200 \mathrm{E}+08$ & 0 & 0 \\
\hline$[2]$ & 0 & $-0,001669$ & $-0,001648$ & $-5,988$ & 0 & 568889 & 0 \\
\hline [3] & 0 & 0 & 4,857E-16 & $-1,123$ & 0 & 0 & 26667 \\
\hline [4] & 0 & $-2,623 \mathrm{E}-15$ & & 16464 & & & \\
\hline [5] & 53333 & $-0,001648$ & & 20,22 & & & \\
\hline [6] & 6667 & 4,857E-16 & & 1,547 & & & \\
\hline$[7]$ & 0 & -0.00005208 & & -8333 & & & \\
\hline [8] & .53333 & $-0,001698$ & & $-14,24$ & & & \\
\hline [9] & 13333 & 0 & & 2,669 & & & \\
\hline
\end{tabular}

Gambar 19. Hasil solving yang disajikan dalam array windows

Hasil perhitungan dengan mengunakan EES menunjukkan bahwa nilai deformasi yang terjadi adalah sebesar $1,70 \mathrm{~mm}$. Nilai ini berbeda 0,31 atau $18,24 \%$ jika dibandingkan dengan nilai deformasi sebesar 2,01 mm dengan menggunakan fine meshing pada ANSYS. Hal ini disebabkan oleh inputan asumsi pada ANSYS yang lebih kompleks. Selain itu diskritisasi elemen pada simulasi dengan ANSYS memungkinkan untuk melakukan perhitungan dengan banyak elemen dan nodes. Sedangkan perhitungan dengan menggunakan EES untuk beban terdistribusi merata, membutuhkan 1 node bantuan untuk melihat besarnya deformasi pada titik tersebut.

\section{Hasil Pemodelan dengan ANSYS}

\section{Meshing Coarse}

Pada pemodelan elemen 2D dengan meshing coarse, dilakukan running atau eksekusi program ANSYS dengan hasil total deformasi pada Gambar 21 dan equivalent stress von mises pada Gambar 22. Gambar 21 memperlihatkan bahwa nilai maksimum total deformasi sebesar 2,0031 $\mathrm{mm}$ di daerah yang ditandai oleh spektrum warna merah (di tengah elemen) dan nilai deformasi minimum (spektrum warna biru) sebesar 1,6693 mm. Gambar 22 menampilkan distribusi tegangan von mises dengan nilai maksimum 35,558 MPa berlokasi di tengah elemen, dan minimum tegangan sebesar 2,9744 MPa di lokasi yang ditandai dengan spektrum warna biru.

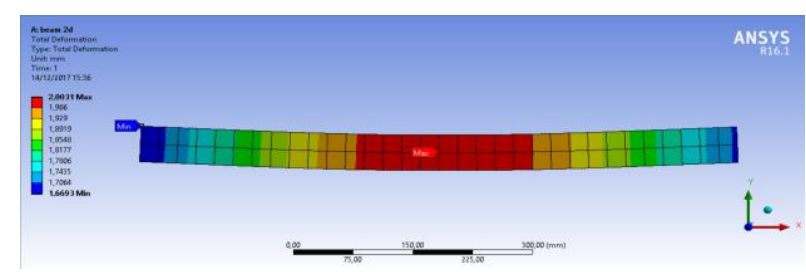

Gambar 21. Distribusi total deformasi dengan coarse meshing

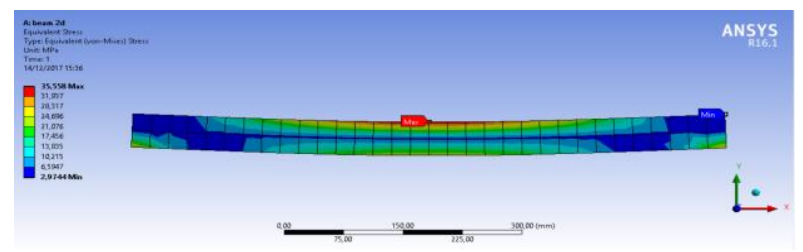

Gambar 22. Distribusi tegangan von mises dengan coarse meshing

\section{Meshing Medium}

Pada pemodelan elemen 2D dengan meshing medium, dilakukan running atau eksekusi program ANSYS dengan hasil total deformasi pada Gambar 23 dan equivalent stress von mises pada Gambar 24. Gambar 23 memperlihatkan bahwa nilai maksimum total deformasi sebesar 2,0078 $\mathrm{mm}$ di daerah yang ditandai oleh spektrum warna merah (di tengah elemen) dan nilai deformasi minimum (spektrum warna biru) sebesar 1,6691 mm. Gambar 24 menampilkan distribusi tegangan von mises dengan nilai maksimum 39,164 $\mathrm{MPa}$ berloaksi di tengah elemen, dan minimum tegangan sebesar 1,5313 MPa dilokasi yang ditandai dengan spektrum warna biru.

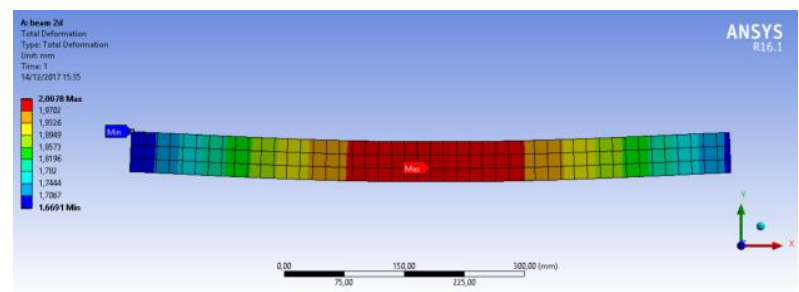

Gambar 23. Distribusi total deformasi dengan medium meshing

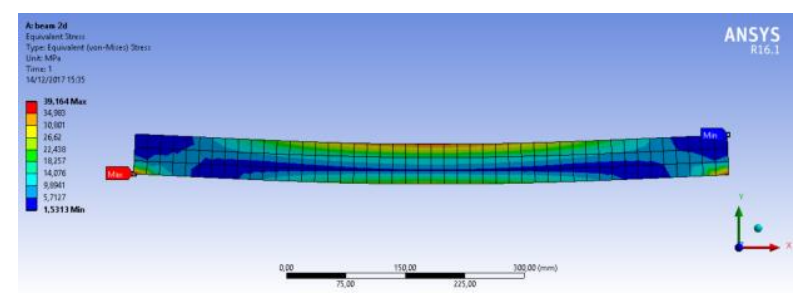

Gambar 24. Distribusi tegangan von mises dengan medium meshing

Hasil deformasi maksimum dengan medium meshing ini memiliki perbedaan dengan meshing coarse dengan persentase sebesar 0,23\% lebih besar. Hasil tegangan maksimum dibandingkan dengan medium meshing juga memiliki persentase 10,14\% lebih besar.

\section{Meshing Fine}

Gambar 25 memperlihatkan bahwa nilai total deformasi maksimum dengan menggunakan meshing fine adalah sebesar 2,0111 mm di daerah yang ditandai oleh spektrum warna merah (di tengah elemen) dan nilai deformasi minimum (spektrum warna biru) sebesar $1,6689 \mathrm{~mm}$. Gambar 26 menampilkan distribusi tegangan von mises dengan nilai maksimum 51,489 MPa terletak di tengah elemen, dan minimum tegangan 
sebesar 0,83173 MPa di lokasi yang ditandai dengan spektrum warna biru.

Hasil deformasi maksimum dengan fine meshing ini memiliki perbedaan dengan meshing medium dengan persentase sebesar $0,16 \%$ lebih besar. Hasil maksimum tegangan dengan fine meshing juga memiliki persentase $31,47 \%$ lebih besar.

Dari ketiga jenis meshing (coarse meshing, medium meshing, dan fine meshing) yang telah dilakukan, terjadi kenaikan pada nilai deformasi maksimum dan tegangan maksimum seiring dengan perubahan kondisi meshing. Nilai deformasi maksimum yang terjadi dari $2,0031 \mathrm{~mm}$ pada coarse meshing sampai dengan 2,0111 mm pada fine meshing menunjukkan bahwa nilai deformasi maksimum mendekati nilai 2,01 dengan perubahan persentase terbesar senilai $0,40 \%$.

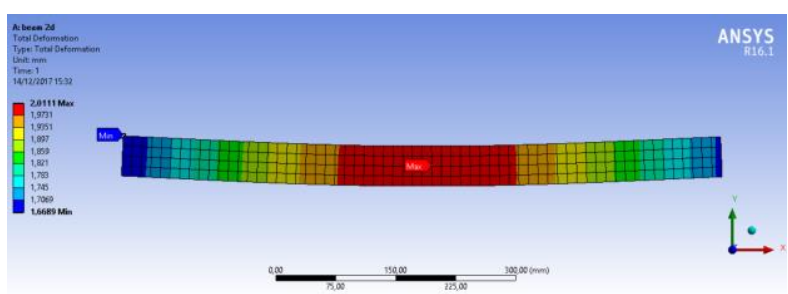

Gambar 25. Distribusi total deformasi dengan fine meshing

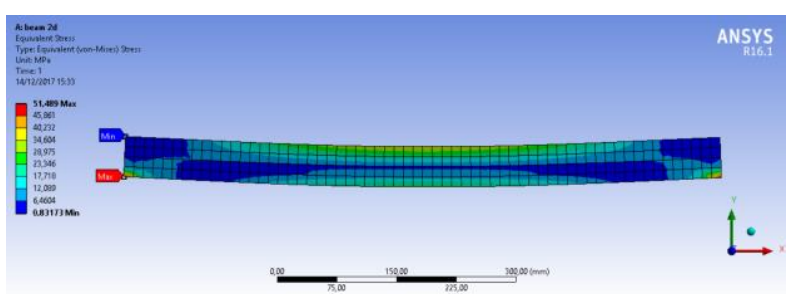

Gambar 26. Distribusi tegangan von mises dengan fine meshing

Nilai tegangan von misses juga menunjukkan adanya kenaikan. Ditunjukkan dengan kenaikan 35,558 $\mathrm{MPa}$ pada coarse meshing menjadi $51,489 \mathrm{MPa}$ pada fine meshing dengan persentase sebesar 44,80\%. Namun nilai ini belum menunjukkan akan mendekati nilai tertentu. Hal ini dikarenakan nilai deformasi sangat mempengaruhi tegangan yang terjadi, kenaikan dalam nilai yang sangat kecil pada nilai deformasi akan berpengaruh sangat signifikan terhadap nilai tegangan. Fenomena ini dibuktikan dengan persamaan tegangan ekuivalen von mises (Persamaan 2). Persamaan 2 menunjukkan bahwa persamaan tersebut merupakan akar dari penjumlahan kuadrat.

$\frac{1}{\sqrt{2}}\left[(\sigma 2-\sigma 1)^{2}+(\sigma 3-\sigma 1)^{2}+(\sigma 3-\sigma 2)^{2}\right]^{\frac{1}{2}} \leq \frac{S y}{n}$

Selanjutnya, nilai tegangan maksimum sebesar 51,489 $\mathrm{MPa}$ masih berada di bawah nilai allowable stress dari material yang digunakan (structural steel) sebesar $160 \mathrm{MPa}$. Sehingga struktur tower penyangga toren dengan kapasitas 500 liter tersebut masih dalam kategori aman untuk diaplikasikan.

\section{Fenomena Fisik Beam}

Dilakukan fenomena fisik beam yang diwakili oleh meshing coarse sebagaimana ditunjukkan pada Gambar 21. Gambar 21 menunjukkan bahwa deformasi total yang terjadi sebesar $2 \mathrm{~mm}$. Untuk mengobservasinya secara lebih detail, deformasi yang terjadi dapat dilakukan secara directional deformation terhadap sumbu X dan terhadap sumbu Y. Directional deformation terhadap sumbu X, seperti pada Gambar 27 memiliki deformasi sebesar 0,054429 mm, Hal ini di karenakan pada initial condition displacement sudah berada pada koordinat X negatif 0,050819.

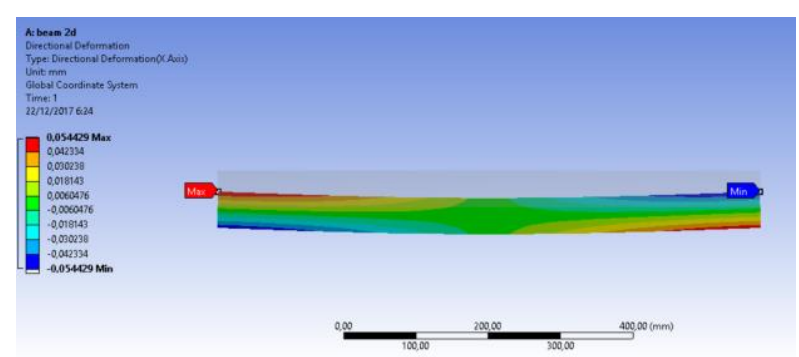

Gambar 27. Directional deformation pada sumbu X

Sedangkan directional deformation pada sumbu Y, seperti yang terlihat pada Gambar 28, memiliki nilai maksimum -1,6694 mm dan nilai minimum -2,1801 $\mathrm{mm}$. Dapat disimpulkan bahwa nilai deformasi tertinggi pada 2,1801 dengan arah ke sumbu Y negatif terjadi pada nilai minimum bertanda spectrum warna biru terletak di tengah beam.

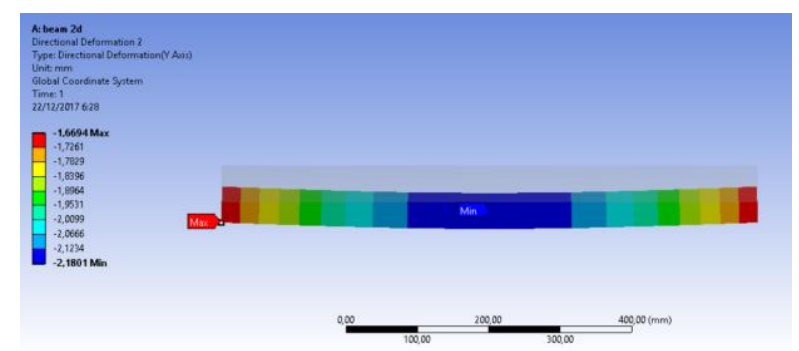

Gambar 28. Directional deformation pada sumbu Y

Gambar 29 merupakan hasil nilai tegangan maksimum pada beam dengan meshing coarse untuk analisis nilai tegangan. Gambar 29 menunjukkan bahwa tegangan maksimum terjadi pada bagian tengah beam bagian atas dan bawah sebesar 44,672 MPa. Dapat disimpulkan bahwa tegangan maksimal yang terjadi memiliki nilai yang sama besar namun dengan arah yang berbeda. Sesuai dengan teori beam bahwa jika terjadi tegangan tekan pada permukaan bagian atas, maka bagian bawah beam akan merespon dengan tegangan tarik sebagai wujud dari reaksi. 


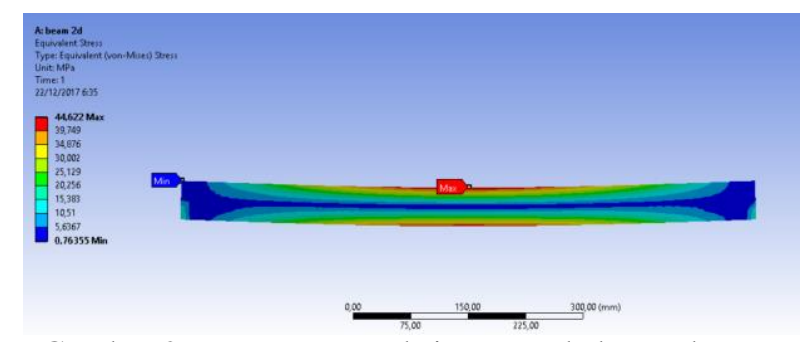

Gambar 29. Tegangan maksimum pada beam dengan meshing coarse

\section{PENUTUP}

\section{Kesimpulan}

Dari hasil analisis dan pembahasan tentang pemodelan metode elemen hingga untuk aplikasi analisis struktur tower penyangga toren, dapat ditarik kesimpulan sebagai berikut:

1) Hasil deformasi dan tegangan von-misses yang terjadi untuk tiap-tiap jenis meshing, dapat dirangkum pada tabel berikut:

\begin{tabular}{|c|c|c|c|}
\hline \multirow{2}{*}{ Output } & \multicolumn{3}{|c|}{ Jenis meshing } \\
\cline { 2 - 4 } & course & medium & fine \\
\hline Deformasi max. (mm) & 2,0031 & 2,008 & 2,0111 \\
\hline Deformasi min. (mm) & 1,6693 & 1,6691 & 1,6689 \\
\hline Tegangan max. (MPa) & 35,558 & 39,164 & 51,489 \\
\hline Tegangan min. (MPa) & 2,9744 & 1,5313 & 0,83173 \\
\hline
\end{tabular}

2) Pada kasus yang telah disimulasikan, verifikasi berhasil dilakukan dikarenakan nilai deformasi yang didapatkan konvergen menuju nilai tertentu dengan maksimal persentase $0,40 \%$.

3) Nilai tegangan maksimum yang terjadi masih berada di bawah allowable stress material $160 \mathrm{MPa}$, sehingga struktur tower penyangga toren dengan kapasitas 500 liter aman untuk digunakan.

4) Hasil perhitungan dengan mengunakan EES menunjukkan bahwa nilai deformasi yang terjadi adalah sebesar $1,70 \mathrm{~mm}$. Nilai ini berbeda 0,31 atau $18,24 \%$ jika dibandingkan dengan nilai deformasi sebesar 2,01 mm dengan menggunakan fine meshing pada ANSYS.

\section{Ucapan Terima Kasih}

Penulis mengucapkan terimakasih kepada: (1) Lembaga Pengelola Dana Pendidikan (LPDP), sebagai penyandang dana beasiswa pendidikan magister penulis; (2) Dr. Ir. Ahmad Indra Siswantara, yang selalu memberikan dukungan terselesaikannya penelitian ini.

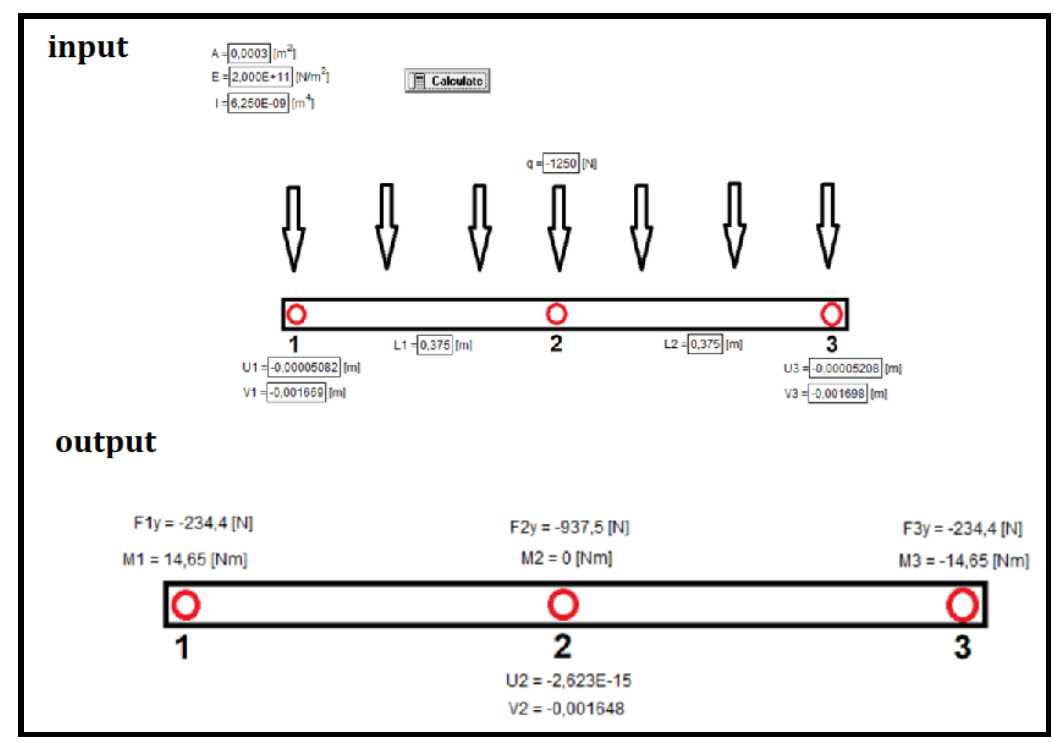

Gambar 20. Hasil solving yang disajikan dalam diagram windows

\section{DAFTAR PUSTAKA}

[1] D. L. Logan, A first course in the finite element method: Cengage Learning, 2011.

[2] S. Moaveni, Finite Element Analysis Theory and Application with ANSYS, 3/e: Pearson Education India, 2011.
[3] W. Hadipratomo, "Dasar-dasar metode elemen hingga," ed: Danamartha Sejahtera Utama, 2005.

[4] E. P. Popov, Engineering mechanics of solids: Prentice Hall, 1990.

[5] S. A. Klein and F. Alvarado, EES: Engineering equation solver for the Microsoft Windows operating system: F-Chart software, 1992. 